\title{
Compassion, Ethics of Care and Legal Rights
}

Jonathan Herring

\begin{abstract}
This article will explore the difficulties facing law in promoting compassion and responding to caring relationships. These include the difficulties in determining whether a person has demonstrated compassion and in enforcing any legal requirement for compassion. The article will use the ethics of care literature to critique two key legal tools: human rights and the concept of best interests. These concepts are typically designed to promote individualistic abstract understandings of the self, which are problematic when used in the setting of intimate relationships. However, this article will suggest that it might not be necessary to abandon the concepts of rights and best interests. They may be useful for setting the boundaries for a space in which appropriate care and compassion can be exercised. It will also be suggested that both rights and best interests are not immune from a relational analysis and might, with appropriate modification, be used to promote the exercise of compassionate relational care.
\end{abstract}

Keywords: Compassion, Care, Relationships

\section{Introduction}

I was once asked to give a lecture on 'how the law can make people compassionate'. At first, I thought that was a very strange topic. Not least because the idea of being cared for by someone compelled to be compassionate under fear of legal sanction sounds horrific. The best I thought the law could do to promote compassion was to 'keep out'. On further reflection, that initial response was too quick.

This article starts by explaining why the idea of using the law to create compassion seems so peculiar to lawyers and will set out the kind of objections most lawyers will have to the notion. I will however argue that these objections are based on a particular model of the law and legal rights. The literature on ethics of care will be used to explore how the law might be more open to seeing the promotion of compassionate relational care as within the legal remit, and what that might mean in practice. In particular, it will consider how the core legal concepts of rights and best interests can be understood in a way which fosters compassionate caring relationships. In focusing on ethics of care I do not mean to deny there may be other forms of ethical analysis that could be used by the law to promote compassion. 


\section{Definition of compassion}

Other articles in this special issue on law and compassion will explore the definition of compassion in detail. So the discussion here of definition will be fairly brief, and given that I am relying on the ethics of care literature, I will in this section focus on the potential differences between compassion and care.

Not surprisingly, many modern discussions of compassion start with Martha Nussbaum's thoughtful consideration of the topic (Nussbaum, 2001, pp. 301, 306). In her book, Upheavals of Thought, she defines compassion as 'the painful emotion occasioned by the awareness of another person's undeserved misfortune' (ibid., p. 301). She explains that this understanding has three cognitive elements: the harm suffered by the other person is serious; the misfortune is not the other person's fault; and that the person is worthy of your concern. In relation to the last factor she notes if a person is responsible for their own harm they deserve blame or reproach, rather than pity.

A rather different understanding can be found in the writing of the Buddhist scholar Geshe Thupten Jinpa, which is used as the basis of the following definition of compassion:

'... a multidimensional process comprised of four key components: (1) an awareness of suffering (cognitive/empathic awareness), (2) sympathetic concern related to being emotionally moved by suffering (affective component), (3) a wish to see the relief of that suffering (intention), and (4) a responsiveness or readiness to help relieve that suffering (motivational).' (Jazaieri et al., 2013, p. 22)

There are plenty of other definitions of compassion, which are considered in the introduction to this special issue, but for the purposes of this article, the focus will be on how compassion differs from care.

Care, of course, is a notoriously difficult concept to define. In earlier work (Herring, 2013a) I have suggested four markers of care: meeting needs; respect; responsibility and 
relationality. To greatly summarize, I see caring as involving the meetings of needs of another; in a way which respects them as a person; which involves acknowledging the responsibilities that come with caring; and which must be understood in the context of a mutual relationship. The nuances of that approach require further analysis, but some will become clear when we compare the concepts of care and compassion. Here are some of the potential differences.

First, it might be argued, as Nussbaum (1996, p. 29) appears to suggest, that compassion is essentially an emotion. Indeed, notably, she sees it as similar to pity. By contrast, caring is usually defined in terms of an activity: meeting a need. This might suggest a clear distinction: compassion being an emotion, while care being an activity. But not all commentators restrict compassion to a feeling. Whitebrook (2002), for example, disagreeing with Nussbaum, argues that compassion inevitably involves an act of care, flowing from awareness of another's suffering. The act of caring is seen as evidence of, an inevitable consequence of, compassion. If a person claims to be compassionate, but does not respond in a caring way to the harm, they cannot genuinely be experiencing compassion. However, so understood compassion is primarily an emotion and, as such, is just the prompter for an act. At most compassion is a desire to help the other, rather than the actual helping (Eisenberg, Van Schyndel and Hofer, 2015). Paul Gilbert argues that in 'current concepts of compassion, most approaches seem to coalesce around the idea that compassion involves a sensitivity to suffering in self and others with a commitment to try to alleviate and prevent it' (Gilbert, 2015, p. 240). This suggests that compassion is tied to a commitment and desire to relieve suffering, but not the act of relief itself. Another way of looking at this distinction is to consider whether it is possible to have an act of care which is not compassionate. For example, consider an exhausted parent, changing a baby's nappy in the middle of night, not full of compassion for the baby, but robotically doing what needs to be done. That might still constitute care, but may be done without compassion. However, it would be wrong to suggest that the state of mind of the parties is irrelevant to care. I have argued that respect (recognising the humanity of the other and responding to their individual needs) is central to care and that requires a degree of empathy. We might conclude, on this discussion that compassion and care are closely linked, but most understandings of care will primarily focus on activities, rather than motivations, while most understanding of compassion primarily focuses on emotions leading 
to care. Nevertheless there is a strong correlation, an act of care which lacks an imagination of the other's suffering and a desire to meet it may lack valuable aspects of care; and compassion which does not lead to a caring act may not genuinely constitute compassion.

Second, the concepts of compassion and care may differ in terms of a power imbalance. Both concepts are open to a concern that the provider of compassion and care is putting themselves in a position of power over the other. On this account, the carer provides care to the person in need; the compassionate person looks down on the disadvantaged and feels sorry for them. Indeed so understood there may be some genuine concerns about both concepts (Käpylä and Kennedy, p. 2014). However, both may be saved from this concern. Ron Paterson (2011) in his helpful consideration of compassion quotes the twelfth century philosopher and physician Maimonides who prayed 'May I never forget that the patient is a fellow creature in pain. May I never consider him merely a vessel of disease'. Here we see a rather different image than the one of the compassionate person looking down on the pitiable one. Compassion here seems to involve a coming alongside and a recognition of fellow humanity, rather than an condescending assessment of another. Similarly, while care might be presented as the exercise of a power by a care giver over a person in need, such an understanding is not necessary (Herring, 2014). In my writing on care (Herring, 2013a; 2014) I have argued against care being seen in terms of there being a carer and a cared for. Instead, I argue in favour of promoting caring relationships in which both parties, maybe in different ways, meet the needs of each other and their interests and identities, becoming intertwined in the context of an intimate relationship. I think the caring relationship model has more scope for the deeply relational understanding between the two while some versions of compassion seems inevitably to involve a separation between the compassionate person and the object of compassion. Dewar et al. claim that compassion 'is not so much about what we choose to do for other people, but what we choose to do together with them' (Dewar et al., 2014, p. 3490), and that opens up the possibility for a more relational approach to compassion, but their discussion at that point becomes the practice of compassion, which might be seen as care, rather than compassion per se. So, both compassion and care carry dangers of justifying the exercise of power by one person over another, although a relational understanding of these concepts may limit this danger. 
Third, as we have seen, compassion on some accounts involves a degree of moral judgment. Nussbaum argues that not 'any and every calamity is an occasion for pity': 'some occasions for pity are illegitimate, and based upon false evaluations', and 'people's judgements about what is happening to them can go wrong in many ways' (Nussbaum, 1996, pp. 45,32 ). She goes on to explain that the 'reflective spectator' should ask whether the harm is deserving of compassion. This suggests that there would be some cases where compassion was not deserved. One should not feel compassion for the rapist who is feeling bad about what he has done. There certainly are some difficulties with Nussbaum's definition when applied in some contexts. The medical professional in a hospital may well not be in a position to determine whether a patient's illness is their fault, indeed we may think it an inappropriate question for them to consider. Such concerns have led some to question whether the kind of judgment referred to by Nussbaum is an essential element of compassion. Care, on the other hand, does not appear to comprise such a judgment. The doctor giving treatment to the criminal who has been involved in a shoot-out with police officers, may be acting in an appropriately caring way, even if the criminal was to blame for the way their injuries came about. However, some may argue that if an individual has competing caring responsibilities in relation to several people an element of judgment of the source of the need might be relevant in some cases.

Fourth, Chris Frakes (2010) argues that care is more restricted than compassion because compassion is needed only when a person has a 'negative condition', whereas care can include 'activities of daily maintenance'. So feeding a hungry teenager may be care, but one need not feel compassion for the hungry teenager. Fifth, Frakes (2010) also argues that compassion is not restricted to those one is currently in a relationship with nor does it lead to an expectation of an on-going intimate relationship. One may feel compassion for the victim of a natural disaster and send money to help, without that generating any long-term relationship. However, relationships of care are commonly seen to involve the acceptance of a degree of responsibility into the future.

As can be seen there are a range of definitions of compassion and care and one might seek to distinguish them in different ways. In this article I will refer to compassionate relational care. This is to make it clear that what I think should be promoted is not simply a 
feeling (compassion) but a putting of compassion into practice (care). The reference to compassion makes it clear that what is being promoted is not simply a task of care (for example, washing someone) but that act done in a compassionate way, in a drawing alongside and recognizing the fellow humanity of the individual. Finally the relational aspect acknowledges that the compassion and the care should flow each way. Each party should be open to and receive the care and compassion of the other, as appropriate. It also makes it clear that the care and compassion can only be understood in terms of the broader relationship between the parties.

I will return to the relevance of these distinctions shortly.

\section{Law and enforcement of compassion}

It is perhaps inevitable following the events at Staffordshire Hospital, England, where extensive neglect and abuse of patients took place in the early 2000s, that there has been a so-called 'crisis of compassion' (Francis, 2013). It is revealing that the law has been called on to provide the solution in promoting compassionate care. In New Zealand there was much debate on whether patients should have a legal right to compassionate care and that legal remedies should be available where they had been treated without compassion (Paterson, 2011). Much could be written on the way law is used as standard response to any perceived social failing. But, I will restrict myself to some fairly obvious points on why the law should not be used to enforce compassion.

First, the law's enforcement mechanisms are typically aimed at preventing harmful behaviour, rather than requiring good behaviour. In short, the law's primary goal is to stop us being little devils, not making us little angels. Tort law does not require us to live up to the highest standards, only the standards of the reasonable person. Criminal law does not (generally) require us to assist those in need, only not to harm people. So, unless it could be shown that a person acting without compassion was causing harm to a patient, prima facie the law would not be interested.

Second, the law focuses primarily on issues which are susceptible to proof. That is, in part, why 'wicked thoughts' are not, per se, unlawful. There is no point in the law seeking to 
regulate a certain kind of behaviour if it is not susceptible to proof. Quite simply, whether a nurse providing treatment to a patient is doing so with compassion or not is not determinable by a court.

Third, even if the above points could both be satisfied, we are still left with the difficulty that the concept of compassion is simply too vague to satisfy the requirements of the rule of law. If the law is going to require individuals to act in a particular way then citizens are entitled to know in advance what the law requires of them. The difficulty is that the concept of compassion is insufficiently clearly defined to provide precise guidance. It is insufficiently clear in two ways. First, the notion of compassion itself is subject to considerable debate and there is no clear consensus on what it means. Second, what is compassionate will depend on the individual one is dealing with. To take a straightforward example, it may be compassionate for a nurse to provide words of comfort to one patient, while that might not be a compassionate way to treat a patient who is a private person and would rather not discuss emotional matters. This increases the difficulty of an actor knowing what is required of them by the law in a particular case.

In light of these points it is not surprising that compassion rarely arises in the law. The limited references are set out elsewhere (for example, Feenan, Bedford and Herring, 2015), and limited largely to law on sentencing or immigration. In the context of medical law, an area where one might expect to find references, there is little reference to it. Most notably perhaps is the NHS constitution (HM Government, 2015) where: 'Respect, dignity, compassion and care should be at the core of how patients and staff are treated'. However, when it comes to the list of rights in the NHS Constitution compassion is not referred to. This seems to reflect the general attitude explained above that it is not the place of the law to require or expect compassion.

Despite these points, I think it would be too quick to conclude that compassion is not relevant for the law. In the following section I argue that the law must seek to foster compassionate relational care.

\section{Why the law must take compassionate relational care seriously}


In the following discussion I will draw from the ethics of care literature (for example, Gilligan, 1987; Friedman, 1993; Tronto, 1993; Bubeck, 1996; Sevenhuijsen, 1998; Noddings, 2002; Feder Kittay, 1999; Groenhout, 2004; Held, 2005; Engster, 2007; Bridgeman, 2009; Herring, 2013a). This approach provides a challenge to the way legal rights and responsibilities are commonly understood. Much of the common law is based on the assumption that we are competent, detached, independent people who are entitled to have our rights of selfdetermination and autonomy fiercely protected (Lloyd, 2004). Legal rights and rules operate to draw boundaries around ourselves and protect us from interference from others. However, the reality is that we are ignorant in important ways, vulnerable, interdependent individuals, whose strength and reality is not in our autonomy, but our relationships with others (Meyers, C., 2004). An approach based on an ethics of care seeks to use these facts as a starting point to the law's response. It starts with a norm of interlocking mutually dependent relationships, rather than an individualised vision of rights (West, 1997, p. 356). Rights and interests are not designed to protect individuals per se, so much as upholding and maintaining networks of caring relationships.

The following points demonstrate why compassionate relational caring relationships must be taken seriously by the law.

\subsection{Compassionate caring relationships are essential to human well-being}

We all have needs and caring for others in meeting needs is a universal experience (Held, 2006). Being in a caring relationship is an inevitable part of being human (Fineman, 2004, p. xvii). The extent of caring may vary during different points in a person's lifetime. There is probably no point in our lives at which we are neither cared for nor are caring for another (Sevenhuijsen, 2003), and often both at the same time (Bridgeman, 2006). Care should be treasured and valued as part of a good life. As Robin West puts it:

'Caregiving labor (and its fruits) is the central adventure of a lifetime; it is what gives life its point, provides it with meaning, and returns to those who give it some measure of security and emotional sustenance. For even more of us, whether or not we like it 
and regardless of how we regard it, caregiving labor, for children and the aged, is the work we will do that creates the relationships, families, and communities within which our lives are made pleasurable and connected to something larger than ourselves.' (West, 2002, p. 89)

Care is of value not just for the individual, but for the wider society. Without caring relationships, the burden that would fall onto the state would be impossible to bear (McClain, 2001; Daly, 2002). As Mona Harrington explains:

'The key idea for a new politics of family care... is to add care to the pantheon of national social values. That is, to assure good care to all members of the society should become a primary principle of our common life, along with the assurance of liberty, equality and justice.' (Harrington, 1999, p. 46)

The law cannot simply ignore compassionate caring relationships which are central to the well-being of society and individuals.

\subsection{Emotions are ethically and practically significant}

In the common law, emotions play relatively little role. Typically the law emphasises the importance of rationality and intellect. The concepts of mental capacity; informed consent; compliance with standards expected by a responsible body of opinion all privilege in legal discourse logical thought and sound judgement. Indeed emotions used to be regarded as in competition with reason. People who were 'emotional' were of doubtful capacity (for example, Re MB [1997] EWCA 1361) and legal reasoning had to be based on cold rationality (Herring and Wall, 2015). There are a number of problems with such an approach. 
First, ignoring emotions does not accord with the reality of human life. The love which goes on caring; the grief, disappointment, frustration, anger and despair, which are all part of life, find no place in an emotion-free rationality. The exclusion of emotion means the voice of carers talking about how their cared for one should be looked after finds no ready legal mouthpiece. The law often struggles to respond to issues which are not readily reducible to an economic value nor expressed in terms of individualised rights. If the law is to respond to real people it must respond in a way which recognizes the importance of emotion.

Secondly, if, as argued above, care is important, then emotions must also be. That is because emotions are central to good care. Trust, sympathy, empathy, sensitivity; such things are essential in compassionate caring relationships. If the legal response to a dilemma undermines these emotions it will undermine the care. A good example of the law failing because it does not consider the role of emotions is the widely acknowledged problems the courts have had in enforcing contact orders (now known as child arrangement orders) in family law. Until recently it seemed that some judges believed that a mother opposing a child having contact with a father would permit contact if they gave her a stern talking to. More recent cases indicate a greater awareness of the emotional complexities involved in such cases ( $R e$ $H B$ [2015] EWCA Civ 389). If the law wants to impact on people's behaviour it must speak to their hearts as well as their minds.

Third, the ethic of care has shown that 'connection, compassion and affectivity should be recognized as important sources of moral reasoning' (Sevenhuijsen, 1998, p. 12). To have capacity we need to value things and people and be able to use these values in decisionmaking (Patrick, 2015). Dr Spock, the Star Trek character, is a source of interest and amusement because he is not affected by emotions. His capacity can be questioned precisely because the emotional part of his decision making is not functioning (Herring and Wall, 2015). As Sevenhuijsen argues: 'connection, compassion and affectivity should be recognized as important sources of moral reasoning' (1998, p. 12). Typically, people are more driven by mixture of both an emotional and rational response (Porter, 2009).

\section{Challenges for the law in incorporating care and compassion}


The points just made indicate why it is particularly important for the law to take into account compassionate relational care. However, some may argue that while the points just made may be helpful for an ethical analysis, they show precisely why the law cannot take compassionate caring relationships into account. It might be argued that law operates when people are in disagreement. Spouses only need lawyers when their relationship breaks down. People only go to court when their relational tools cannot provide a solution. Is not an approach based on promoting caring relations particularly inappropriate in a legal system which is trying to resolve disputes between people whose relationship has broken down? Further, the law in its nature is based on abstract principles and rules which apply across the board. The kind of tailoring of responses to the individual features of the case is impossible or unrealistic in the court room. I disagree.

The law can, and indeed should take account of compassionate caring relationships in the following ways.

\subsection{The influence of law outside the court room}

It is obviously true that law is primarily aimed at influencing people who do not come to court. To take a trivial example, the law on illegal parking impacts on a far larger range of people than simply those who receive parking fines. Criminal law is designed, in large part, to deter people from committing crime. Contract law is designed to deter people from breaching a contract or guide parties as to how to (extra-judicially) resolve disputes if a breach has taken place. The law on who can marry sends powerful messages to society about what standards of behaviour are expected in the law. In family law it indicates what kinds of relationships are approved of and why. Hence the intense debate over same-sex marriage. Legal regulations and the messages from them force or nudge people in various ways. They provide generalised guidance as to how people arrange their interactions. Court cases are but a small part of how the law operates. Law can therefore be used powerfully to encourage people to act in a way which will promote caring relationships. A particularly good example might be the law dealing with how those lacking mental capacity will be treated. It sends a reasonably clear message 
that decision makers should seek to promote the best interests of the person lacking capacity in making decisions on their behalf.

While therefore we might not expect the law to be involved in promoting compassionate caring relationships by bringing short-tempered nurses to the court to be fined, the law can be involved in creating an environment in which compassionate caring relationships flourish - just as contract law plays a role in creating an environment in which contracts are respected. Crawford et al. (2014) have claimed that although nurses may enter the profession with considerable empathy, organisation and professional limits hinder their exercise of compassion. Healthcare systems with their emphasis on marketization, and command-and-control models, can restrict compassionate care (Crawford et al., 2014). A culture among health care professions, a focus on meeting service standards, and an emphasis on market values can all crowd out the opportunities for compassion. Matters such as promoting time-efficient care and maximal use of resources can lead to a skewing of perspectives. In a health care setting it might be that law could require or encourage: seeking feedback from patients; ensuring staff feel valued and cared for and safe; identifying and celebrating compassionate care practices; integrating caring conversation into job descriptions (Dewar et al., 2015). This approach recognizes that rather that blaming individual practitioners for lacking compassion (which involves many of the difficulties outlined above) we look at the healthcare environment and processes which might facilitate compassionate caring relationships (Crawford et al., 2014).

Similarly, through the provision of state support and financial protections; we can design our state support mechanisms in a way following an ethics of care. We are beginning to see support through welfare payments for those who undertake care of others, although this is limited. Employment law is offering protection to those who undertake paid work and have caring responsibilities. I have discussed elsewhere (Herring, 2013a) the broad range of areas in which this might make the task of compassionate caring relationships easier and less a source of social disadvantage.

\subsection{Rethinking rights}

A core concept used in the common law is rights. The traditional approach requires us to analyse the rights of each individual in each case. However, one of the messages from the 
ethics of care literature is that people are relational. They do not seek to promote only their own interests, not because they are 'selfless' but because their interests are tied up with the interests of others. They cannot seek to promote their own interests with no attention paid to others. It is the improvement of their relationships they seek. The writing on compassion emphasizes that at its heart there is a pain at the suffering of another and a desire to remedy that in so far as is possible. In experiencing such an emotion a person's well-being becomes connected to another. In relationships of caring and dependency, interests become intermingled (Herring, 2014). We do not break down into 'me' and 'you'.

The traditional legal method of setting out the claims of rights of each party do not match how people understand their personal lives. It is not consistent with compassionate caring relationships in which individuals do not see issues as involving clashes of individual rights or interests, but rather as a working through of relationships (Bridgeman, 2009). The muddled give and take of everyday caring life where sacrifices are made and benefits gained, without them being totted up on some giant familial star chart, chimes more with everyday life than the image of independent interests and rights. As Diana Meyers puts it, the self:

'is the interpersonally bounded self... As relational selves... people share in one another's joys and sorrows, give and receive care, and generally profit from the many rewards and cope with the many aggravations of friendship, family membership, religious or ethnic affiliation, and the like. These relationships are sources of moral identity, for people become committed to their intimates and to others whom they care about, and these commitments become central moral concerns.' (Meyers, 2004, p. 299)

Traditional conceptions of rights might be thought to be inconsistent with compassionate caring relationships. Rights are traditionally seen as attached to individuals and promoting individual rights such as autonomy and privacy; aimed at keeping people separate and free. These are seen to promote an individualist conception of people. Rights tend to focus on the 
right at a particular time and consider whether any interference is justified that point in time. It also assumes that we can separate out each party's rights, whereas as argued above in compassionate caring relationships individuals' rights are not separate. Rights can also mean that 'real experiences' are converted into 'empty abstractions' (Tushnet, 1984, p. 1364). As Carol Smart puts it: 'the rights approach takes and translates personal and private matters into legal language. In so doing, it reformulates them into issues relevant to law rather than to the lives of ordinary people' (Smart, 2003, p. 238). Jennifer Nedelsky explains:

'The selves to be protected by rights are seen as essentially separate and not creatures whose interests, needs, and capacities are mutually constitutive. Thus, for example, one of the reasons women have always fit so poorly into the framework of liberal theory is that it becomes obviously awkward to think of women's relation to their children as essentially one of competing interests to be mediated by rights.' (Nedelsky, 2008, p. 145)

Despite these concerns, rights are not completely without use for an ethics of care perspective. Rights might provide the tools needed to provide the framework to enable safe relationships to develop and flourish. Martha Minow and Mary Lyndon Shanley (1996, p. 16) argue that a relational concept of rights would embrace the individual as both separate and as situated within a web of relationships of care, attachments and interdependency, and to understand the family as a unit determined both by the individuals of which it is comprised and by the existing social, political and historical context. This conceptualisation of rights enables us to understand parties to compassionate caring relationships both as individuals with rights to be protected and as dependent upon the love and care of others.

Virginia Held, writing from an ethics of care perspective, explains:

'I now think that caring relations should form the wider moral framework into which justice should be fitted. Care seems the most basic moral value [...] Without care [...] there would be no persons to respect and no families to improve [...] Within a network 
of caring, we can and should demand justice, but justice should not push care to the margins, imagining justice's political embodiment as the model of morality, which is what has been done.' (Held, 1996, pp. 71-72)

Our starting point is therefore the necessity for care and the promoting of caring relationships. These generate responsibilities. Only then do rights come as tools to enable people to perform their responsibilities and enable relationships to be genuinely caring. Jennifer Nedelsky argues that,

'The relational approach redresses this historical imbalance by making clear that what rights in fact do and have always done is construct relationships-of power, of responsibility, of trust, of obligation. Legal rights can protect individuals and the values that matter to them, but they do so by structuring the relations that foster those values. Thus all rights, the very concept of rights, are best understood in terms of relationship.' (Nedelsky, 2008, p. 146)

Rights could be used to promote more relational values. The relational perspective is primarily interested in cases where two people are involved and that will be where their rights clash. In this balancing exercise is there room for relational values to have weight? The nature of the balancing exercise in cases where the rights of individuals under the European Convention on Human Rights (ECHR) conflict has produced some complex jurisprudence. A popular view is that the courts must undertake a 'parallel analysis' of the rights involved (Choudhry and Herring, 2010). The starting point is to look at the interests of each individual and consider whether they engage a right under the ECHR: the point being that not every interest an individual has is necessarily protected by a right under the ECHR. If the interest does engage a right then the court will need to consider whether an infringement of that right is justified. This process will provide the solution, if there is only one person's right which cannot be justifiably interfered with. 
However, in difficult cases the above process may produce a clash between two rights neither of which can justifiably be infringed. Rachel Taylor and I (2006) suggest that a principled balancing of rights can be achieved by focusing on the values that underlie each right. If we see in cases which involve people in intimate caring relationships, that relationships are the key value, we can argue that the value of relational promotion should be among law's central values. This would introduce a relational element into the rights- based approach which would be key in the difficult cases where the rights of individuals clash.

Another point that would be emphasized from an ethics of care perspective is that responsibilities are more important than rights. In compassionate relational care responsibilities take on a key role. People seeing others in need; feeling compassion and caring will not understand their role in terms of rights. Or, at least if there are rights these exist to enable compassionate caring relationships to exist. Supporters of an ethic of care argue that rather than the primary focus of the legal or ethical enquiry being whether it 'is my right to do X?', the question should be 'what is my proper obligation within the context of this relationship?' (Held, 2006, p. 15). Rather than the law promoting people's freedom from responsibility, the focus should be on how the law can enable people to fulfil their responsibilities. Rights primarily exist to enable people to carry out their responsibilities (Williams, 2002).

The classic liberal perspective is that one is 'born free' and that any responsibilities one takes must be in some sense voluntarily assumed (Davison, 1993). However, for an ethics of care approach, with its starting point being that people are relational, then the supposition is that there will be responsibilities for others. We are born into relationships which carry responsibilities with them. So the response to a person in need is not an assessment of the extent to which you might owe them an obligation to assist, but rather an assessment of how one can meet that need, given other caring responsibilities (Sevenhuijsen, 2000).

\subsection{Rethinking best interests}


I have just explored how rights could be re-thought of in a way which is more compatible with the promotion of compassionate relational care. The same can be said of another important concept in the common law: the concept of best interests. This is used by the courts in cases where the individual $(\mathrm{P})$ cannot make a decision for themselves because they lack capacity to do so. In such a case the court can determine what is in P's best interests. This too, in its traditional understanding, has been seen in an individualistic way. The best interests test has been interpreted by the courts to mean that, P's best interests are the sole consideration. The court will therefore pursue the course which best promotes the interests of $P$, regardless of the impact on the interests of others. However, in practice courts have found ways of protecting interests of parents and carers while adhering to the welfare/best interests principle (Herring, 1999).

I have written previously in favour of relational-based welfare (for a detailed discussion see Herring, 1999; 2013b; Foster and Herring, 2015). This is based on the idea that P's interests are best promoted when they are cared for in healthy relationships. Under such an approach, cases can be resolved by recognising and acting in the person's interests whilst heeding carers' interests and the integrity of the family as a whole. If carers were to take every decision for P considering only P's welfare, that would not in fact promote the P's welfare. Would anyone wish to be raised in a way that placed enormous burdens on our carers in order to promote our welfare, maybe just the tiniest bit? (Foster and Herring, 2015) We would accept that a decision might be made which on a particular occasion was not in our best interests, but which was part of a fair give -and-take in the relationships. Relationship-based welfare provides a means of holding onto the welfare or best interests principle while respecting the rights and interests of caregivers.

\subsection{The importance of communicative law}

A central aspect of compassionate relational care is that each person seeks to meet the needs of the other in a relational context. That will mean listening to each other and finding the solution that will work in the context of the relationship and the individuals within that relationship. This means that what might be an appropriately caring response in one case might not work in a different context with a different set of people. A solution must be found 
which works within the particular relational context. This means that one of the key aspects of care ethics is the rejection of abstract rules.

Instead we should start with the context and concrete reality of the particular situations and the individuals and their relationships and characteristics. This may require a detailed consideration of the history of the relationship between the parties and what responsibilities will have arisen as a result of that history. We need to look at the history of the relationship to work out what will be a fair sharing of the benefits and burdens of the relationship. In doing this, consideration may need to be given to an individual's other caring responsibilities.

In an important article Professor Judge Anselm Eldergill (2015) has argued that compassion is an important part of judging. He accepts that traditionally judging is seen as involving rational-based decision making and a degree of detachment from the case at hand. However, he makes a convincing case for arguing that in some cases at least it is necessary for the judge to seek to understand the position in which the individual before the court finds themselves in. If an effective response is to be made to the situation the parties are in the judge needs to learn something of their beliefs and values. Without doing so any order a court makes is likely to be ineffective. This was recently emphasised in the family law context in England and Wales, where the Supreme Court has stressed the importance of the court seeking to identify the order which will promote the interests of the particular child before the court. In Re B (A Child) [2013] UKSC 33 the Supreme Court rejected the use of presumptions about what generally works for children, on the basis that this provided the court with little guidance on what would promote the welfare of the particular child at the centre of the case.

In several cases recently we have seen judges undertake a traditional legal judgement, but at the end make comments specifically addressing the parents. In $\operatorname{Re} K, H H$ (children) [2013] EWHC 165 (Fam), Pauffley J. said:

'I express my profound sadness that the outcome of this court process has been to deny the grandparents and parents their heartfelt wish. If I had believed there was a 
sufficient basis to be optimistic about the children's future with the Fs, I should not have decided as I have. The tragedy is that the prospects of such a placement would involve enormous risks which, on behalf of these two very vulnerable children, I simply could not take' (para. 57).

Here we see the judge appreciating the impact of her decision on the grandparents and expressing to them her compassion. There was no need for such a comment to be made and it is rare to find such a comment in judgements, but it might show the parents that the judge was not unfeeling and had understood the strength of their feelings.

In Re HB [2015] EWCA Civ 389, the Court of Appeal, in refusing to order contact, added:

` urge the parents, the mother in particular, to think very carefully about everything we have said, not only in these judgments but also during the hearing of the appeal, when each of them was present in court. Unless they can, as they must, even at this late stage, sort things out and restore the father's relationship with $\mathrm{J}$ and $\mathrm{K}$, the future for all of them is bleak. There will be no winners here; all will be losers.

$\mathrm{J}$ and $\mathrm{K}$ have an image of their father which, however it has come about, is distorted and profoundly damaging to them. But it is unrealistic for anyone, the mother included, to imagine that this state of affairs will continue indefinitely. Sooner or later, and it may be much sooner than the mother believes or would wish, the children will come to discover the full story of their parents' failures. Sooner or later, and it may be much sooner than the mother believes or would wish, the children will demand to see the court papers and to read the judgments. What will they think? How will they react? In particular, what will the children think, how will they react, when they discover, as one day they will, that their father is not the man they currently believe him to be? Will they then turn against their mother? Will they reject both parents? The mother 
needs to ponder these questions and think hard about what the answers might be.' (paras. 80-81)

Two things in particular are notable about these comments. First, the judge is seeking to understand why the parents are acting in the way they are. She realises that traditional legal principle is not going to affect the behaviour of the parents. She is showing compassionate care in seeking to articulate principles which will be of meaning and value to the particular parents before the court. Second, these arguments are designed to promote the compassionate care by the parents. They recognise that parents care deeply about their children and indeed that is why family disputes can become so acrimonious. The judges in these cases are seeking to encourage the parents to exercise their compassionate care to achieve the result. I hasten to add, there may be questions over whether or not the judiciary should be encouraging parental contact in these cases, but that is a debate for elsewhere. What is notable is that the judge in these cases is both exercising compassionate care and seeking to encourage compassionate care.

\section{Conclusion}

This article has argued that although there are good reasons why the law should not compel people under threat of sanction to engage in compassionate relational care, that does not mean there is no role for the law in encouraging people to do so; to protect their interests where they do; and create an environment where it is valued and supported. Indeed, I have argued that there is a very strong case for the law doing so. The law can do this by sending messages that can influence people's attitudes; by ensuring that court interventions make emotional sense as well as rational sense; and rethinking the concepts of rights and best interests in a more relational way. The law at its most basic level is dealing with and responding to people. People are governed by their emotions, and caring relationships play a key part in their lives. This will require a major restructuring of the law and society (see Herring 2013a for detailed proposals of what this would involve). The primary aim will not 
then not be economic productivity, but the promotion and protection of caring compassionate relationships.

*Exeter College, University of Oxford, jon.herring@law.ox.ac.uk

\section{References}

BRIDGEMAN, J. (2006) 'Book Review', Feminist Legal Studies 14: 407-410.

BRIDGEMAN, J. (2009) Parental Responsibility, Young Children and Healthcare Law. Cambridge: Cambridge University Press. 
BUBECK, D. (1996) Care, Gender and Justice. Oxford: Oxford University Press.

CHOUDHRY, S. and HERRING, J. (2010) European Human Rights and Family Law. Oxford: Hart. CRAWFORD, P., BROWN, B., KVANGARSNES, M. and GILBERT, P. (2014) 'The Design of Compassionate Care', Journal of Clinical Nursing 23: 3589-3599.

DALY, M. (2002) 'Care as a Good for Social Policy', Journal of Social Policy 31: 251-268.

DEWAR, B., ADAMSON, E., SMITH, S., SURFLEET, J. and KING, L. (2014) 'Clarifying Misconceptions about Compassionate Care', Journal of Clinical Nursing 23: 3489-3599.

DEWAR, B., ADAMSON, E., SMITH, S., SURFLEET, J., KING, L. (2015) ‘Clarifying Misconceptions about Compassionate Care', Journal of Advanced Nursing 70(8): 1738-1747.

EISENBERG, N, VAN SCHYNDEL, S. and HOFER, C. (2015) 'The Association of Maternal Socialization in Childhood and Adolescence with Adult Offsprings' Sympathy/Caring', Developmental Psychology 51: 7-16.

ELDERGILL, A. (2015) 'Compassion and the Law: a Judicial Perspective', Elder Law Journal 3: 268-278.

ENGSTER, D. (2007) The Heart of Justice. Care Ethics and Political Theory. Oxford: Oxford University Press.

FEDER KITTAY, E. (1999) Love's Labour: Essays on Women, Equality and Dependency. Abingdon: Routledge.

FEENAN, D., BEDFORD, D. and HERRING, J. (2105) 'Judicial Compassion', Elder Law Journal 4: 392-398.

FINEMAN, M. (2004) The Autonomy Myth. New York: New Press.

FOSTER, C. and HERRING, J. (2015) Altruism, Welfare and the Law. Amsterdam: Springer.

FRAKES, C. (2010) 'When Strangers Call: A Consideration of Care, Justice, and Compassion', Hypatia 25: 79-99. 
FRANCIS, R. (2013) Report of the Mid-Staffordshire NHS Foundation Trust Public Inquiry. The Stationary Office: London, England.

FRIEDMAN, M. (1993) 'Liberating Care', in M. Friedman, (ed.) What Are Friends For. Ithaca, NY: Cornell University Press, 142-183.

GILBERT, P. (2015) 'The Evolution and Social Dynamics of Compassion', Social and Personality Psychology Compass 9: 239-254.

GILLIGAN, C. (1987) 'Moral Orientation and Moral Development', in E. FEDER KITTAY and D. T. MEYERS (eds), Women and Moral Theory. New York: Rowman and Littlefield, 19-23.

GROENHOUT, R. E. (2004) Connected Lives: Human Nature and an Ethics of Care. London: Rowman and Littlefield.

HARRINGTON, M. (1999) Care and Equality: Inventing a New Family Politics. New York: Alfred A. Knopf.

HELD, V. (2005) The Ethics of Care: Personal, Political, and Global. New York: Oxford University Press.

HERRING, J. (2014) 'The Disability Critique of Care', Elder Law Review 2.

HERRING, J. (2013a) Caring and the Law. Oxford: Hart Publishing.

HERRING, J. (2013b) 'Forging a Relational Approach: Best Interests or Human Rights?', Medical Law International 13: 32-54.

HERRING, J. (1999) 'The Human Rights Act and the Welfare Principle in Family Law Conflicting or Complementary?' Child and Family Law Quarterly (1999) 11: 223-242.

HERRING, J. and WALL, J. (2015) 'Autonomy, Capacity and Vulnerable Adults: Filling The Gaps in the Mental Capacity Act', Legal Studies 35: 698-719.

HM GOVERNMENT (2015) The NHS Constitution, London, The Stationary Office. 
JAZAIERI, H., McGONIGAL, K., JINPA, T., DOTY, J., GROSS, J., GOLDIN, P. (2014) 'A Randomized Controlled Trial Of Compassion Cultivation Training: Effects On Mindfulness, Affect, and Emotion Regulation' Motivation and Emotion 38: 23-35.

KÄPYLÄ, J. and KENNEDY, D. (2014) 'Cruel to Care? Investigating the Governance of Compassion in the Humanitarian Imaginary', International Theory 6: 255-292.

LLOYD, L. (2004) 'Mortality and Morality: Ageing and the Ethics of Care', Ageing and Society 24: $235-24$.

MCCLAIN, L. (2001) 'Care as a Public Value: Linking Responsibility, Resources, and Republicanism', Chicago-Kent Law Review 76(3): 1673-1731.

MEYERS, C. (2004) 'Cruel Choices: Autonomy and Critical Care Decision-Making', Bioethics 18(2): 104- 119.

MEYERS, D. T. (2004) 'Narrative and Moral Life' in C. Calhoun (ed) Setting the Moral Compass. Oxford, Oxford University Press, 299-318.

MINOW, M. and SHANLEY, M. (1996) 'Relational Rights and Responsibilities: Revisioning the Family in Liberal Political Theory and Law', Hypatia 11: 4-29.

NEDELSKY, J. (2008) 'Reconceiving Rights and Constitutionalism', Journal of Human Rights 7: 139-173.

NODDINGS, N. (2002) Starting at Home: Caring and Social Policy. Berkeley: University of California Press.

NUSSBAUM, M. (1996) 'Compassion: The Basic Social Emotion', Social Policy and Philosophy 13: $27-41$.

NUSSBAUM, M. (2001) Upheavals of Thought: The Intelligence of Emotions. Cambridge: Cambridge University Press.

PATERSON, R. (2011) 'Can We Mandate Compassion?' Hastings Centre Report 41(2): 20-23.

PATRICK, C. (2015) 'A New Synthesis for Law and Emotions: Insights from the Behavioral Sciences', Arizona State Law Journal 47: 1239-1287. 
PORTER, E. (2009) 'Can Politics Practice Compassion?’ Hypatia 21: 97-123.

SEVENHUIJSEN, S. (2003) 'The Place of Care: The Relevance of the Feminist Ethics of Care for Social Policy' Feminist Theory 4: 179-197.

SEVENHUIJSEN, S. (2000) 'Caring in the Third Way: The Relation between Obligation, Responsibility and Care in Third Way Discourse', Critical Social Policy 20(1): 5-37.

SEVENHUIJSEN, S. (1998) Citizenship and the Ethics of Care: Feminist Considerations on Justice, Morality and Politics. Abingdon: Routledge.

SMART, C. (2003) 'Children and the Transformation of Family Law' in J. Dewar and S. Parker, Family Law Processes, Practices, Pressures. Oxford: Hart, 238-239.

TAYLOR, R. and HERRING, J. (2006) 'Relocating Relocation' Child and Family Law Quarterly 18: 517-536.

TRONTO, J. (1993) Moral Boundaries: A Political Argument for an Ethic of Care. Abingdon: Routledge.

TUSHNET, M. (1984) 'An Essay on Rights', Texas Law Review 62: 1363-1403.

WEST, R. (1997) Caring for Justice. New York: New York University Press.

WEST, R. (2002) 'The Right to Care' in E. Feder Kittay (ed), The Subject of Care: Feminist Perspectives on Dependency. Lanham: Rowman \& Littlefield, 89-103.

WHITEBROOK, M. (2002) 'Compassion as a Political Virtue', Political Studies 50: 529-544.

WILLIAMS, F. (2002) 'The Presence of Feminism in the Future of Welfare', Economy and Society 31: 502-519. 